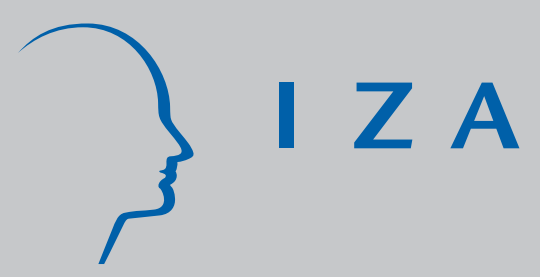

IZA DP No. 2489

Macroeconomic Effects of Short-Term Training Measures on the Matching Process in Western Germany

Reinhard Hujer

Christopher Zeiss

December 2006 


\title{
Macroeconomic Effects of Short-Term Training Measures on the Matching Process in Western Germany
}

\author{
Reinhard Hujer \\ Goethe University of Frankfurt, \\ ZEW Mannheim and IZA Bonn \\ Christopher Zeiss \\ Goethe University of Frankfurt
}

\author{
Discussion Paper No. 2489 \\ December 2006
}

\author{
IZA \\ P.O. Box 7240 \\ 53072 Bonn \\ Germany \\ Phone: +49-228-3894-0 \\ Fax: +49-228-3894-180 \\ E-mail: iza@iza.org
}

\begin{abstract}
Any opinions expressed here are those of the author(s) and not those of the institute. Research disseminated by IZA may include views on policy, but the institute itself takes no institutional policy positions.

The Institute for the Study of Labor (IZA) in Bonn is a local and virtual international research center and a place of communication between science, politics and business. IZA is an independent nonprofit company supported by Deutsche Post World Net. The center is associated with the University of Bonn and offers a stimulating research environment through its research networks, research support, and visitors and doctoral programs. IZA engages in (i) original and internationally competitive research in all fields of labor economics, (ii) development of policy concepts, and (iii) dissemination of research results and concepts to the interested public.
\end{abstract}

IZA Discussion Papers often represent preliminary work and are circulated to encourage discussion. Citation of such a paper should account for its provisional character. A revised version may be available directly from the author. 
IZA Discussion Paper No. 2489

December 2006

\section{ABSTRACT \\ Macroeconomic Effects of Short-Term Training Measures on the Matching Process in Western Germany}

This paper investigates the macroeconomic effects of short term training measures on the matching processes in West Germany. The empirical analysis is based on regional data for local employment office districts for the period from January 2003 to December 2004. The empirical model relies on a dynamic version of a matching function augmented by short term training measures. In order to obtain consistent estimates in the presence of a dynamic panel data model and endogenous regressors, GMM estimation methods are applied.

JEL Classification: J64, J24, I28, C41, C14

Keywords: $\quad$ training measures, active labor market policy, panel data

Corresponding author:

Christopher Zeiss

Chair of Statistics and Econometrics

Johann Wolfgang Goethe-University Frankfurt/Main

Faculty of Economics and Business Administration

P.O. Box 111932

D-60054 Frankfurt/Main

Germany

Email: zeiss@wiwi.uni-frankfurt.de 


\section{Introduction}

The Federal Employment Agency (Bundesagentur für Arbeit, FEA) spends a significant share of its annual budget - about 19.5 billion euros ( 36 percent) in 2004 - on attempting to improve the employment opportunities of about 2.5 million people participating in a number of different active labor market policy (ALMP) programs. In line with the orientation towards programmes that should support the integration into regular employment, short term training measures (TM, Maßnahmen der Eignungsfeststellung und Trainingsmaßnahmen) have become the most important instrument of ALMP with about 1.2 million newly promoted individuals in 2004. TM support unemployed and persons threatened by unemployment with a set of different courses and activities. This set comprises, e.g., aptitude tests, courses teaching presentation techniques for job applicants as well as traditional training courses providing specific skills and techniques. According to the legal basis, TM aim to improve the prospects for integration into employment. TM are separated into different modules that either attempt to support the job-placement on part of the employment agency as well as the self-contained job-search of the participants, or should adjust the qualification of the participants to the demands of the market. Therefore, TM generally aim to improve the prospects of job search.

In the view of spending's of about 469 million euro (2004) and the severe unemployment problem in Germany, the question whether TM effectively achieve the indented goals is most important for policy makers. The following analysis aims to estimate the aggregate impacts of TM by a macroeconometric evaluation. A macroeconometric evaluation identifies the aggregate impacts of an ALMP programme via the variation of the intensity by which the programme is utilised over time and regions. To estimate the aggregate impacts of TM we use an augmented version of the matching function. The matching function summarises the matching process, i.e., the simultaneous search of unemployed workers who search for vacant jobs and firms with vacant jobs that search for appropriate workers. The analysis allows us to assess if TM help to increase the aggregate number of transitions from unemployment into regular employment.

Compared to a microeconometric evaluation that accounts explicitly for individual characteristics, a macroeconometric evaluation allows us to account for possible effects on non-participants. Such effects are an important issue, in particular, if a programme is used on a large scale so spillover effects on non-participants are likely. In the case TM affect the group of non-participants the overall effect of the programme, i.e., the composite impact on participants and non-participants, cannot be estimated by a microeconometric evaluation. A possible negative effect of TM that affects the non-participants is a substitution effect that arises if hirings from the stock of participants replace hirings from the stock of regular (untreated) unemployed. In the presence of a pure substitution effect a microeconomic evaluation would lead to a positive effect on the individual transition rate from unemployment into employment, although the aggregate number of transitions from unemployment into employment would be unchanged.

The following analysis serves as a supplement to the existing microeconometric evaluations. This regards, in particular, the analysis by Hujer, Thomsen, and Zeiss (2006), who estimate the effects of TM on the individual unemployment duration. As noted by Bellmann and Jackman (1996), the augmented matching function approach is complementary to a duration analysis on the microeconomic level. The 
results from the microeconometric evaluations by Biewen, Fitzenberger, Osikominu, and Waller (2006) and Hujer, Thomsen, and Zeiss (2006) point towards a positive effect of TM on the individual level, i.e., TM increase the employment probability and reduce the unemployment duration respectively. Major task of the following aggregate impact analysis is to examine if these impacts can also be found on the macroeconomic level.

The econometric analysis of the macroeconomic effects of TM is based on an aggregate regional panel data set taken from the FEA, where the regional units are defined by the administrative areas of the local offices of the FEA. With the available data we are able to estimate the augmented matching function with a linear dynamic panel data model. To estimate the parameters of the model consistently, we apply the first-difference GMM estimator as proposed by Arellano and Bond (1991) and the system GMM estimator as proposed by Blundell, Bond, and Windmeijer (2000). The application of the these GMM estimators allow us to account for the possible endogeneity of the explanatory variables. In particular, for the policy measure we assume that these are determined by a policy reaction function, and thus need to be treated as an endogenous variable.

The reminder of the paper is as follows. In the next section we present some stylized facts about TM in Germany. Section three presents the matching function augmented by TM that is the key element of our empirical analysis as well as a brief description of the regional panel data set. Section four, that contains the empirical analysis, starts with a discussion of the econometric issues which arise for dynamic panel data models, and proceeds with the presentation of the estimation results. Finally section five concludes.

\section{Short Term Training in Germany}

TM were introduced with the enaction of Social Code III (Sozialgesetzbuch III) in 1997/1998, see $\S \S 48$ 52. They replaced the former short-term qualification measures (kurzzeitige Qualifizierungsmaßnahmen), training measures for unemployment assistance/benefit recipients and employment counseling measures (Maßnahmen der Arbeitsberatung). The primary purpose of TM is to improve the integration prospects of the participating individuals. For this reason, programs consist of three different types of measures (modules) that can be accomplished separately or in combination and allow a flexible implementation in line with the specific needs of the job seekers and the options of the local employment agencies as well.

The first module involves aptitude tests (Eignungsfeststellungen) that last for up to four weeks. These tests are used to assess the suitability of job seekers in terms of skills, capability and labor market opportunities for employment or training. The measures of the second module of TM aim at improving the applicant's presentation and job search abilities (Überprüfung der Verfügbarkeit/Bewerbertraining). The activities support the individual's efforts to find work or efforts by the employment agency to place him/her, especially through job-application training, counseling on job search possibilities or measures assessing the unemployed person's willingness and ability to work (work-tests). Measures of the second module are promoted for up to two weeks. The last module contains practical training of the participants (for up to eight weeks) providing necessary skills and techniques required for placement in employment 
or vocational training (Vermittlung notwendiger Kenntnisse und Fertigkeiten). The courses cover specific working techniques (e.g., business administration), computer courses and language courses. Combinations of modules, e.g., a job aptitude test followed by a computer course, could be granted for a maximum of twelve weeks. TM are provided by service providers (Bildungsträger) and firms and this ensures that activities are closely related to the market. Referring to the official statistics of the FEA, in 2005 about 34 percent of the participants joined programs in the first, about 19 percent in the second, and about 28 percent in the third module. Combinations amounted to 18 percent of all support action. Furthermore, more than 95 percent of the participating individuals complete the TM; the main reason may be the short duration of programs.

Financial support is provided by FEA and covers course costs, examination fees, travel grants as well as child care. In addition, participants receive unemployment insurance (UI) payments or maintenance allowances if not entitled to UI. Decisions about support of courses and placement of job seekers are made by the employment agencies. Support is authorized on recommendation or with the approval of the agency only and activities are often initiated by caseworkers. However, TM may be initiated by job seekers, service providers or firms as well. A program is not eligible for support if it is intended to facilitate the re-recruitment (in a socially insured position for more than three months within a period of four years) of the unemployed person by their former employer or if the employer has offered a job to the unemployed person before the current unemployment spell. Moreover, to avoid deadweight losses, support is denied if the service provider could be expected to take on the participant without support action in TM or if placement of suitable experts is possible.

Caseworkers possess a great deal of discretion in the allocation of participants and it is consequently interesting to know on what basis they reach their decisions. According to Kurtz (2003) who has interviewed a number of caseworkers about their preferences, objectives and reasons for offering TM, the most important factors are the placement chances of the individual after participation, the compensation of missing (professional) qualification, the improvement of integration chances, but also previous knowledge as well as motivation of job seekers. The results indicate that caseworkers regard preceding unemployment duration as being of minor importance for placement. Similar to the majority of ALMP programs, TM are offered to job seekers facing barriers to employment in particular, e.g., long-term unemployed. Higher educated people (with university degree) are less likely to be regarded as suitable TM candidates.

The growing importance of TM within ALMP in Western (and Eastern) Germany is clearly demonstrated in Table 1 which presents the number of entries into the three most important ALMP programs as well as the unemployment rates for the years 2000 to 2004. While the economy in Eastern Germany has been plagued by unemployment rates of 17.1 (2000) to 18.4 percent (2003), the analogous figures for Western Germany were 7.2 (2001) to 8.5 percent (2004). The development of the ALMP mix reflects this regional difference as well. In Western Germany, the focus is on programs that aim to adjust the qualification of the individuals to meet the demands of the market. The emphasis in Eastern Germany is on employment programs designed to relieve the tense situation of the market. In both regions - but particularly so in the west, the number of TM has increased significantly. In 2000, TM have been the second most important program with 285 (201) thousand people promoted in Western (Eastern) Ger- 
Tab. 1: Entries into Selected Almp Programmes and UnemployMENT RATES IN 2000-2004

\begin{tabular}{lrrrrr} 
& 2000 & 2001 & 2002 & 2003 & \multicolumn{1}{c}{2004} \\
\hline \hline Germany & & & & & \\
\hline Short-term Training Measures & 485,339 & 551,176 & 864,961 & $1,064,293$ & $1,188,369$ \\
Vocational Training Programmes & 522,939 & 441,907 & 454,699 & 254,718 & 185,041 \\
Job Creation Schemes & 265,563 & 194,633 & 162,737 & 146,824 & 153,021 \\
\hline Unemployment Rate (in percent) & 9.6 & 9.4 & 9.8 & 10.5 & 10.6 \\
\hline East Germany & & & & & \\
\hline Short-term Training Measures & 200,712 & 232,261 & 351,867 & 373,930 & 399,836 \\
Vocational Training Programmes & 213,654 & 188,423 & 195,533 & 93,676 & 61,089 \\
Job Creation Schemes & 181,395 & 130,147 & 119,869 & 115,300 & 112,921 \\
\hline Unemployment Rate (in percent) & 17.1 & 17.3 & 17.7 & 18.5 & 18.4 \\
\hline West Germany & \multicolumn{5}{r}{} \\
\hline Short-term Training Measures & 284,627 & 318,915 & 513,094 & 690,363 & 788,533 \\
Vocational Training Programmes & 337,880 & 261,199 & 259,166 & 161,042 & 123,952 \\
Job Creation Schemes & 78,684 & 61,890 & 42,862 & 31,515 & 40,079 \\
\hline Unemployment Rate (in percent) & 7.5 & 7.2 & 7.7 & 8.4 & 8.5 \\
\hline \hline
\end{tabular}

Source: Bundesagentur für Arbeit $(2003 ; 2005)$.

many behind vocational training programs. Five years later, TM are the largest program with 789 (400) thousand participants (2004). This strong rise of TM has been accompanied by a tailing off in the use of more traditional programs and reflects the reforms of German ALMP in 1998 and the following years. ${ }^{1}$ The main reason for this reform was the high and persistent unemployment associated with tense budgetary pressures on the FEA. Until the end of the 1990s, vocational training programs and job creation schemes (Arbeitsbeschaffungsmaßnahmen) have been the most important ALMP programs in Germany. They have become less important as both are long term in nature (up to three years) and expensive. ${ }^{2}$ TM are clearly shorter and program costs are much lower than for other measures. In 2004 (2003), the FEA spent 496 (577) million euros on TM; the average costs per participant and month amounted to 538 euros (Bundesagentur für Arbeit, 2006).

\section{Specification and Data}

\subsection{The Augmented Matching Function}

Key element of the aggregate impact analysis is the matching function augmented by TM. The matching function serves as an approximation of the matching process, i.e., the search of firms with vacant jobs for workers, and the search of unemployment workers for vacant jobs [see Petrongolo and Pissarides (2001)]. Similar to a classical production function the matching function determines the number of job-matches by two input arguments, the stock of unemployment and the stock of vacancies. In our analysis we rule out job-to-job transitions, so the number of job-matches are equal to the inflows from unemployment to employment. In order to analyse the impacts of TM on the aggregate transitions from unemployment

\footnotetext{
${ }^{1}$ Since 1998, the legal basis for ALMP in Germany has been amended twice. In 2002, new instruments and a more 'activating' labor market policy were introduced; from 2004 onwards the four laws Modern Services on the Labor Market (Hartzreforms) have been enacted to reach the goals of Lisbon treaty from March 2000.

${ }^{2}$ In comparison, the spending of the FEA on vocational training programs (job creation schemes) amounted to 3,616 $(1,212)$ million euros in 2004. Costs per participant and month in 2004 were $1,573(1,179)$ euros.
} 
to employment, we augment the matching function by a measure that represents the intensity by which the policy maker employs TM. The augmented matching function was proposed by Lehmann (1995), Bellmann and Jackman (1996) and Puhani (1999). Using a Cobb-Douglas specification the augmented matching function can be written as

$$
m=A v^{\beta_{v}}(c u)^{\beta_{u}}
$$

where $m$ denotes the inflows from unemployment into regular employment, $v$ is the stock of vacancies, $u$ is the stock of unemployed, $A$ is a scale parameter, $c$ is a search effectiveness parameter and the elasticities with respect to $c u$ and $v$ are denoted with $\beta_{u}$ and $\beta_{v}$. The variables $m, v$ and $u$ are measured relative to the labour force. The scale parameter $A$ is interpreted as a mismatch parameter that captures several determinants of the matching process like the differences in geographic and skill characteristics or the preferences and the institutional set incentives which influences the search behaviour (Puhani, 1999).

In order to introduce TM as a policy instrument into the empirical model we assume that TM affect the search effectiveness of the unemployed. Hujer, Thomsen, and Zeiss (2006) show with a standard search model that if TM are successful they can positively affect the transition rate from unemployment into employment, that is participants search more effectively. Since participants in TM are registered as unemployed the stock of unemployed consists of participants and nonparticipants. Therefore, we assume that the stock of effective searching unemployed is given by $c u$, and that the policy-maker can affect the search effectiveness parameter $c$ via the intensity at which TM are allocated to unemployed. Search effectiveness is specified as $c=\mu(1+\tau p)$, where the parameter $\mu$ represents the search effectiveness of the unemployed in the absence of TM, and the impact of TM on the search effectiveness is determined by a measure for the intensity of the TM allocation $p$ times an impact parameter $\tau$. The log-linearised form of equation (1) can be approximated for small $\tau p$ as

$$
\ln m=\alpha+\beta_{v} \ln v+\beta_{u} \ln u+\theta p
$$

where $\alpha=\ln A+\beta_{u} \ln \mu$ and $\theta=\beta_{u} \tau^{3}$

The econometric analysis of the macroeconomic effects of TM on the matching process is based on equation (2). Since the empirical analysis is done with a regional panel data set, we introduce a regional index $i=(1,2, \cdots, N)$ and a time index $t=(1,2, \cdots, T)$. Furthermore, we include additional explanatory variables $x_{i t}$ in order to account for the structure of labour supply and a residual term $\omega_{i t}$ that captures unobserved determinants. As additional variables we include the share of young $(<25)$, elderly $(>55)$ and long term unemployed relative to the stock of unemployment, as well as the participants in alternative ALMP programmes relative to the stock of unemployment. The alternative ALMP programmes we account for are vocational training programmes ('Förderung der beruflichen Weiterbildung', FbW), job creation schemes ( 'Arbeitsbeschaffungsmaßnahmen' ABM, 'Strukturanpassungsmaßnahmen' SAM, 'Beschäftigungschaffende Infrastrukturmaßnahmen' BSI) and subsidised employment programmes ('Eingliederungszuschüsse' EGZ, 'Eingliederungszuschüsse bei Neugründung' EZN). We include the participants in alternative ALMP programmes into the augmented matching function, in order to account for a possible correlation of the general activity of the regional employment agency with the

\footnotetext{
${ }^{3}$ For small $\tau p$ we can use $\ln (1+\tau p) \approx \tau p$.
} 
extend by which the agency employs TM. A more active regional agency, i.e., one that utilises ALMP to a greater extend compared to other regions, might be more successful in placing unemployed to regular jobs, either by a more efficient placement service or by successful ALMP programmes. If these agencies allocate TM to a greater extend as well, we would obtain an omitted variable bias in the case we do not include a measure for the general activity of the regional agency.

The econometric model is given by

$$
\gamma(L) \ln m_{i t}=\alpha+\beta_{v} \ln v_{i t-1}+\beta_{u} \ln u_{i t-1}+\theta(L) p_{i t}+\xi x_{i t-1}+\omega_{i t},
$$

where $\gamma(L), \alpha, \beta_{v}, \beta_{u}, \theta(L)$ and $\xi$ are parameters to be estimated. In order to account for partial adjustment processes on the labour market we specify a dynamic equation with $\gamma(L)=1-\gamma L$, where $L$ denotes the lag operator. The policy measure $p_{i t}$ enters the equation with several lags, where $\theta(L)=$ $\theta_{0}+\theta_{1} L+\theta_{2} L^{2}+\cdot+\theta_{q} L^{q}$ is a polynomial in the lag operator with lag length $q$.

Equation (3) combines flow and stock variables. Whereas the flow variable $m_{i t}$ represents the inflows from unemployment into employment within month $t$ relative to the labour force at the end of month $t$, the variables $v_{i t}$ and $u_{i t}$ represent the stock of vacancies and unemployed at the end of month $t$ relative to the labour force at the end of month $t$. We assume that the inflows into employment in $t$ are generated from the available vacancies and unemployed at the beginning of $t$, so it is reasonable to include both variables with one lag [see also Blanchard and Diamond (1989)]. Furthermore, this specification avoids endogeneity problems with respect to unemployment and vacancies (Petrongolo and Pissarides, 2001). For the same reason we include the additional variables in $x_{i t}$ with one lag as well.

As a measure for the intensity by which TM are utilised, we use the inflows from unemployment into TM within month $t$ relative to the stock of registered unemployed at the end of month $t$. This indicator can be interpreted as the probability to be assigned into a TM faced by a regular unemployed person. Major advantage of the inflows into TM is that they are fully under the control of the policy maker. In contrast, policy measures like the stock of participants in a programme relative to the unemployed or the expenditures for the programme [see e.g. Calmfors and Skedinger (1995) or Boeri and Burda (1996)] are not fully under control of the policy maker, since these measures depend on both, the former inflows into the programme and the outflows out of the programme.

A further important issue for the empirical analysis is the lag structure of the programme measures. It is not realistic to assume that the aggregate programme effect is constant over time. For example, if an individual enters a TM, the programme may induce a locking-in effect or may need some time to become effective. Therefore, with the inflows into programme as policy measure, the effect on the inflows into employment may differ for several lags. To account for possible different effects of TM over time, we include the policy measure with several lags. We include the policy measure from the actual period up to the eleventh lag, i.e., we set $q=11$. With this lag-length we can discover the sequence of impacts within the first year after an extension of the inflows into TM. Furthermore, the choice is such that it overlaps the maximum programme length ( 3 months), so the analysis allows us to account for possible locking-in effect.

At this point we have to note, that the analysis of the matching function does not consider possible effects on the outflows from employment. The outflows from employment would be affected if, e.g., firms 
lay-off their employees in order to replace them by hirings from stock of participants. ${ }^{4}$ However, such an effect requires that a programme improves the qualification by far enough, so the costs of replacing an employee are compensated by the productivity gains. In general, only long-term training programmes are intended to improve the qualification of the participants, whereas TM primarily focus on the support of job-search process. Therefore, an impact of TM the on outflows from employment is not very likely and we will not consider them in the following analysis.

\subsection{Data}

The econometric analysis is based on an aggregate regional panel data set taken from the FEA. The regional units are defined by the administrative areas of the local offices of the FEA. For the 141 regional units in Western Germany we observe monthly time series data from January 2003 up to December 2004, i.e., for each region we face a time series of 24 months. Table 2 contains the descriptive statistics for the available data.

Tab. 2: DESCRIPTIVE STATISTICS

\begin{tabular}{lrrrr} 
& West Germany & & & \\
Variable & Mean & Min & Max & Std. \\
\hline \hline Number of Labour Office Districts: 141 & & & & \\
Number of Observations: 3384 & & & & \\
Time Range: 1:2003 - 12:2004 (Monthly Data) & & & & \\
\hline \hline Inflows into Employment $\left(m_{i t}\right)$ & $0.5 \%$ & $0.2 \%$ & $2.5 \%$ & $0.2 \%$ \\
Unemployment $\left(u_{i t}\right)$ & $8.4 \%$ & $3.8 \%$ & $16.8 \%$ & $2.3 \%$ \\
Vacancies $\left(v_{i t}\right)$ & $0.8 \%$ & $0.2 \%$ & $5.9 \%$ & $0.5 \%$ \\
& & & & \\
Inflows into Training Measures $\left(p_{i t}\right)$ & $2.4 \%$ & $0.3 \%$ & $10.2 \%$ & $1.3 \%$ \\
Additional Explanatory Variables $\left(x_{i t}\right)$ & & & & \\
- Young Unemployed $(<25)$ & $12.5 \%$ & $5.2 \%$ & $20.6 \%$ & $2.3 \%$ \\
- Elderly Unemployed $(>55)$ & $24.3 \%$ & $17.8 \%$ & $30.9 \%$ & $2.1 \%$ \\
- Long-Term Unemployed & $32.0 \%$ & $9.4 \%$ & $51.5 \%$ & $6.9 \%$ \\
- Participants in Alternative ALMP's & $8.2 \%$ & $2.5 \%$ & $23.8 \%$ & $2.4 \%$ \\
& & & & \\
Labour Force & 233269 & 75121 & 1178463 & 141172 \\
\hline \hline$m_{i t}, v_{i t}$ and $u_{i t}$ measured in percent relative to the labour force. & & \\
$p_{i t}$ and $x_{i t}$ measured in percent relative to registered unemployment. &
\end{tabular}

In order to estimate the aggregate impacts of TM on the inflows into regular employment we correct the available data with respect to the inflows from unemployment into registered employment. In Germany all participants in ALMP programmes that are associated with a registered employment, e.g., job creation schemes or subsidised employment, are recorded as employed by the official statistic of the FEA. Hence, the official inflows from unemployment into registered employment include the inflows from unemployment into these ALMP programmes. For the empirical analysis we remove the inflows from unemployment into the most important ALMP programmes that are associated with a registered employment from the inflows into registered employment. The programmes we consider are the major

\footnotetext{
${ }^{4}$ Layard, Nickell, and Jackman (1991) call this effect a substitution effect if workers are replaced within the same firm, or refer to a displacement effect if firms that hire workers from the stock of participants replace firms that hire workers from the stock of regular unemployed.
} 
job creation schemes (ABM, SAM, BSI) and subsidised employment programmes (EGZ, EZN).

A final concern regards the official vacancy data of the FEA. In the absence of mandatory registration of vacancies our data conveys only information on those vacancies which are voluntary reported to the labour offices by private or governmental employers. As presented by Kettner and Spitznagel (2006) only $31 \%$ of the vacancies in West Germany are reported to the labour office in 2004. Hence, the official vacancy data is severely underreported. However, a correction of the vacancy data as suggested by Franz and Smolny (1994) is not possible for our regional panel data. Therefore, the vacancy data is subject to a measurement error that we have to account for in the empirical analysis.

\section{Econometric Analysis}

\subsection{Methodology}

In order to estimate equation (3) we have to consider some methodological issues which arise in the context of linear dynamic panel data models. To simplify the further notation we denote with $m_{i t}^{*}$ the logarithm of the inflows from unemployment into regular employment relative to the labour force, and with $v_{i t}^{*}$ and $u_{i t}^{*}$ the logarithm of vacancies and unemployment relative to the labour force. For convenience the econometric model (3) is reproduced here

$$
\gamma(L) m_{i t}^{*}=\alpha+\beta_{v} v_{i t-1}^{*}+\beta_{u} u_{i t-1}^{*}+\theta(L) p_{i t}+\xi x_{i t-1}+\omega_{i t} .
$$

For the residual term $\omega_{i t}$ which captures the unobserved determinants we consider a one-way error component model with

$$
\omega_{i t}=\eta_{i}+e_{i t} .
$$

That is, we assume that the unobserved determinants are separable into an error term $e_{i t}$ that varies over $i$ and $t$, and a time constant and regional specific error term $\eta_{i}$ that varies only over $i$. Furthermore, we assume for the error components that

$$
E\left(e_{i t}\right)=0, E\left(\eta_{i}\right)=0, E\left(e_{i t} \eta_{i}\right)=0 \text { for } i=(1, \cdots, N) \text { and } t=(q+1, \cdots, T),
$$

where $q=11$ denotes the lag length in (4) and that $e_{i t}$ is not serial correlated, i.e.,

$$
E\left(e_{i t} e_{i s}\right)=0 \text { for } i=(1, \cdots, N) \text { and } t \neq s .
$$

In addition we make a standard assumption concerning the initial conditions with respect to the dependent variable:

$$
E\left(m_{i s}^{*} e_{i t}\right)=0 \text { for } i=(1, \cdots, N), t=(q+1, \cdots, T) \text { and } s=(1, \cdots, q) .
$$

Regarding the explanatory variables we generally allow them to be correlated with the error component $\eta_{i}$. In linear dynamic panel data models this is basically the case since the lagged dependent variable is correlated with the error component by construction. For the explanatory variables we assume that $v_{i t}^{*}, u_{i t}^{*}, p_{i t}$ and $x_{i t}$ are endogenously determined:

$$
\begin{aligned}
& E\left[\left(v_{i t}^{*}, u_{i t}^{*}, p_{i t}, x_{i t}\right)^{\prime} e_{i s}\right]=0 \text { for } s<t \text { and } \\
& E\left[\left(v_{i t}^{*}, u_{i t}^{*}, p_{i t}, x_{i t}\right)^{\prime} e_{i s}\right] \neq 0 \text { for } s \geqslant t \text { and } i=(1, \cdots, N), t=(q+1, \cdots, T) .
\end{aligned}
$$


For the unemployment rate, the vacancy rate and the additional explanatory variables in $x_{i t}$, this simply follows from the fact that the inflows from unemployment into employment within month $t$ naturally affect the stocks of the variables $u_{i t}^{*}, v_{i t}^{*}$ and $x_{i t}$ at the end of month $t$. Moreover, as we mentioned in the previous section the vacancy rate suffers from a measurement error due to the underreporting problem, so that it is reasonable to treat the vacancy rate as an endogenous variable. Note, that under assumption (9) we can treat all variables as weak exogenous regressors that enter equation (4) with lags.

Also, with respect to the policy measure we assume that $p_{i t}$ is an endogenous variable. The endogeneity of $p_{i t}$ stems from two sources. First, individuals who leave unemployment towards employment within month $t$ most likely do not enter a TM within $t$. Second, generally ALMP are assumed to be determined by a policy reaction function with the state of the labour market as an input argument (Calmfors and Skedinger, 1995). Therefore, most empirical studies on the macroeconomic effects of ALMP use instrumental variable estimators in order to account for the endogeneity of the ALMP measures [see for example Calmfors and Skedinger (1995) and Boeri and Burda (1996)]. Since we include the contemporary policy measure $p_{i t}$ as explanatory variable into the econometric model, we deal with at least one endogenous variable in equation (4).

Analogously to the dependent variable we make the following assumption concerning the initial conditions of the explanatory variables

$$
E\left[\left(v_{i s}^{*}, u_{i s}^{*}, p_{i s}, x_{i s}\right)^{\prime} e_{i t}\right]=0 \text { for } i=(1, \cdots, N), t=(q+1, \cdots, T) \text { and } s=(1, \cdots, q) .
$$

Due to the presence of endogenous and weakly exogenous variables which are furthermore assumed to be correlated with the regional specific error term a simple OLS-estimation would lead to inconsistent results. Also a transformation of the model that removes the regional specific error component and a subsequent OLS-estimation of the transformed model leads to inconsistent results. Such a transformation can be the within-transformation $y_{i t}^{+}=y_{i t}-(1 / T) \sum_{t=1}^{T} y_{i t}$, or the first-differences operator $\Delta y_{i t}=(1-L) y_{i t}$. Since the within-transformation removes the mean over time, the transformed variables $\left(m_{i t-1}^{*+}, v_{i t-1}^{*+}, u_{i t-1}^{*+}, p_{i t}^{+}, x_{i t-1}^{+}\right)$are correlated with the transformed error term $e_{i t}^{+}$by construction. Similarly, the model in first differences also suffers from a correlation of $\Delta m_{i t-1}^{*}, \Delta v_{i t-1}^{*}, \Delta u_{i t-1}^{*}, \Delta p_{i t}$, $\Delta p_{i t-1}, \Delta x_{i t-1}$ with $\Delta e_{i t}$.

In order to estimate the parameters of the model consistently we apply the GMM-estimators as suggested by Arellano and Bond (1991), Blundell and Bond (1998) and Blundell, Bond, and Windmeijer (2000). In comparison to standard instrumental variable estimators as suggested, e.g., by Anderson and Hsiao (1981) these estimators are efficient with weaker assumptions with respect to the error term and have shown to perform superior in finite samples. In particular we will use the first-difference GMM estimator proposed by Arellano and Bond (1991) and the system GMM estimator suggested by Blundell, Bond, and Windmeijer (2000).

In order to remove the regional specific error component the first-difference GMM estimator considers the transformed model

$$
\gamma(L) \Delta m_{i t}^{*}=\beta_{v} \Delta v_{i t-1}^{*}+\beta_{u} \Delta u_{i t-1}^{*}+\theta(L) \Delta p_{i t}+\xi \Delta x_{i t-1}+\Delta e_{i t} .
$$

With the assumptions (5)-(10) we can impose the following moment conditions relying on the equations 
in first differences

$$
E\left[\mathbf{z}_{i t-s} \Delta e_{i t}\right]=0 \text { for } t=q+2, \cdots, T \text { and } 2 \leqslant s \leqslant t-1,
$$

where $\mathbf{z}_{i t}$ is the $(1 \times J)$ vector $\left(m_{i t}^{*}, v_{i t}^{*}, u_{i t}^{*}, p_{i t}, x_{i t}\right)$.

Although the two-step first-difference GMM estimator is consistent and asymptotically efficient, in finite samples it often has shown to perform poorly. Monte-Carlo simulations by Blundell and Bond (1998) and Blundell, Bond, and Windmeijer (2000) have shown that the coefficient for the lagged depended variable tends to be underestimated. The bad finite sample performance of the first-difference GMM estimator results from a weak instruments problem, which arises from the poor explanatory power of the instruments in levels for the equations in first differences. Blundell, Bond, and Windmeijer (2000) have shown, that a weak instruments problem can arise if the time series are highly persistent, or if the variance of $\eta_{i}$ increases relative to the variance of $e_{i t}$. In our model, highly persistent patterns can be found for the most stock variables (e.g. the unemployment and vacancy rate). Thus, for these variables the explanatory power of the instruments in levels may be questionable. In contrast, the second problem concerns both stock and flow variables. If a large part of the variance of the explanatory variables stems from the variation of the regional specific unobserved heterogeneity, the variables in levels are again poor instruments for the variables in first differences, where the regional specific variation is removed.

To overcome this weak instruments problem, additional moment conditions were suggested, e.g., by Ahn and Schmidt (1995), Arellano and Bover (1995), Blundell and Bond (1998) and Blundell, Bond, and Windmeijer (2000). Ahn and Schmidt (1995) suggested additional non-linear moment conditions based on the assumption of the absence of serial correlation. Arellano and Bover (1995), Blundell and Bond (1998) and Blundell, Bond, and Windmeijer (2000) suggested additional linear moment conditions for the equation in levels which are based on assumptions on the initial conditions. In the following we consider the additional moment conditions in levels and the associated system GMM estimator as proposed by Blundell and Bond (1998) and Blundell, Bond, and Windmeijer (2000). According to Blundell, Bond, and Windmeijer (2000) the additional moment conditions in levels result from an assumption that imposes a restriction on the initial conditions:

$$
E\left[\eta_{i} \Delta \mathbf{z}_{i s}\right]=0 \text { for } s=(2, \cdots, q+1) \text { and } i=(1, \cdots, N) .
$$

That is, the first differences of the initial conditions of the instruments $\mathbf{z}_{i t}$ are assumed to be uncorrelated with the regional error component. Under assumption (13) the following linear moment conditions, which relate to the equations in levels are valid.

$$
E\left[e_{i t} \boldsymbol{\Delta} \mathbf{z}_{i t-s}\right]=0 \text { for } t=(q+1, \cdots, T) \text { and } 1 \leqslant s \leqslant t-2 .
$$

Calculation of the system GMM estimator using the full set of moment conditions (12) and (14) is based on a stacked system comprising the $(T-q-1)$ equations in first differences and the $(T-q)$ equations in levels.

The first-difference and system GMM estimators are both linear estimators. The efficient two-step estimates are calculated with an optimal weighting matrix that is calculated from the residuals of a consistent one-step estimator [see Blundell, Bond, and Windmeijer (2000)]. Monte-Carlo simulations 
have shown that the asymptotic standard errors of the two-step estimates are seriously downward biased in small samples [see e.g. Arellano and Bond (1991)]. As noted by Windmeijer (2005) the expression for the estimated asymptotic covariance matrix neglects the extra variation in finite samples due to the presence of estimated parameters in the efficient weight matrix. To allow for a reliable inference we use a finite sample correction of the estimated covariance matrix for the two-step estimates proposed by Windmeijer (2005). As Bond and Windmeijer (2002) and Windmeijer (2005) have shown, the corrected standard errors often provide more reliable inference based on the two-step estimates, with size properties similar to those of the estimated one-step standard errors.

A final issue when estimating the model (4) concerns the number of moment conditions that increase with the time series dimension $T$. The available data consists of a relatively large time dimension for the given number of regions in West Germany. As a result we face a huge number of moment conditions for both GMM estimators. As noted by Arellano and Bond (1991) using too many instruments may lead to an (small sample) overfitting bias. In particular, Arellano and Bond (1998) emphasize that in the case the model contains endogenous regressors, using too many instruments can result in seriously biased estimates. Therefore, we decided to reduce the number of moment conditions related to the equations in first differences. For the first-difference GMM and the system GMM estimator we cut the history of the instruments related to the equations in first differences. For $m_{i t}^{*}$ we cut the history after $t-4$ and for $p_{i t}$ after $t-12$. For the remaining instruments $v_{i t}^{*}, u_{i t}^{*}$ and $x_{i t}$ we used the respective levels at $t-2$ and $t-3$ as instruments. That is, for the variables $v_{i t}^{*}, u_{i t}^{*}$ and $x_{i t}$ we impose the moment conditions $E\left[\left(v_{i t-s}^{*}, u_{i t-s}^{*}, x_{i t-s}\right) \Delta e_{i t}\right]=0$ for $s=2,3$, which are not imposed separately for each $t$. In particular, these instruments are similar to those suggested by Anderson and Hsiao (1981).

\subsection{Empirical Results}

The estimation results are presented in table 3. The table contains the estimation results for the withingroups estimator (WITHIN), the first-difference GMM estimator (DIF-GMM) and the system GMM estimator (SYS-GMM). In order to account for time specific effects all estimations are based on the transformed model, where time specific effects are removed by the transformation $y_{i t}^{++}=y_{i t}-(1 / N) \sum_{i=1}^{N} y_{i t}$.

We start our analysis with the coefficient for the lagged dependent variable. For all estimators we find a positive and significant coefficient between 0.4 and 0.5 . Since the within estimator for the lagged dependent variable is known to be downward biased for fixed $T$ [see Nickell (1981)], it can be used as a benchmark for the GMM estimators. As expected we obtain for the downward biased WITHIN the lowest coefficient, followed by a slightly larger coefficient for DIF-GMM, and the highest coefficient is obtained from SYS-GMM.

Regarding the coefficients for the unemployment and vacancy rate, we find throughout positive and significant coefficients. Thus, for West Germany the results clearly support the existence of a matching function that determines the inflows into employment by unemployment and vacancies. Noteworthy is that the coefficient for the unemployment rate is relatively large compared to the very low coefficient for the vacancy rate. ${ }^{5}$ Obviously, the estimates for the elasticities with respect to unemployment and

\footnotetext{
${ }^{5}$ See Petrongolo and Pissarides (2001) for an overview of the results obtained from several empirical studies of the matching
} 
vacancies are affected by the underreporting problem of the vacancies.

Turning to the estimated coefficients for the inflows into TM we find for all estimators a positive and significant coefficient for $p_{i t}$. For WITHIN we find further significant positive coefficients for $p_{i t-2}$, $p_{i t-10}$ and $p_{i t-11}$, and for DIF-GMM we find significant positive coefficients for $p_{i t-2}, p_{i t-11}$. A single negative coefficient is obtained for $p_{i t-1}$ from SYS-GMM. Thus, most of the significant coefficients point towards a positive effect of TM on the inflows from unemployment into employment.

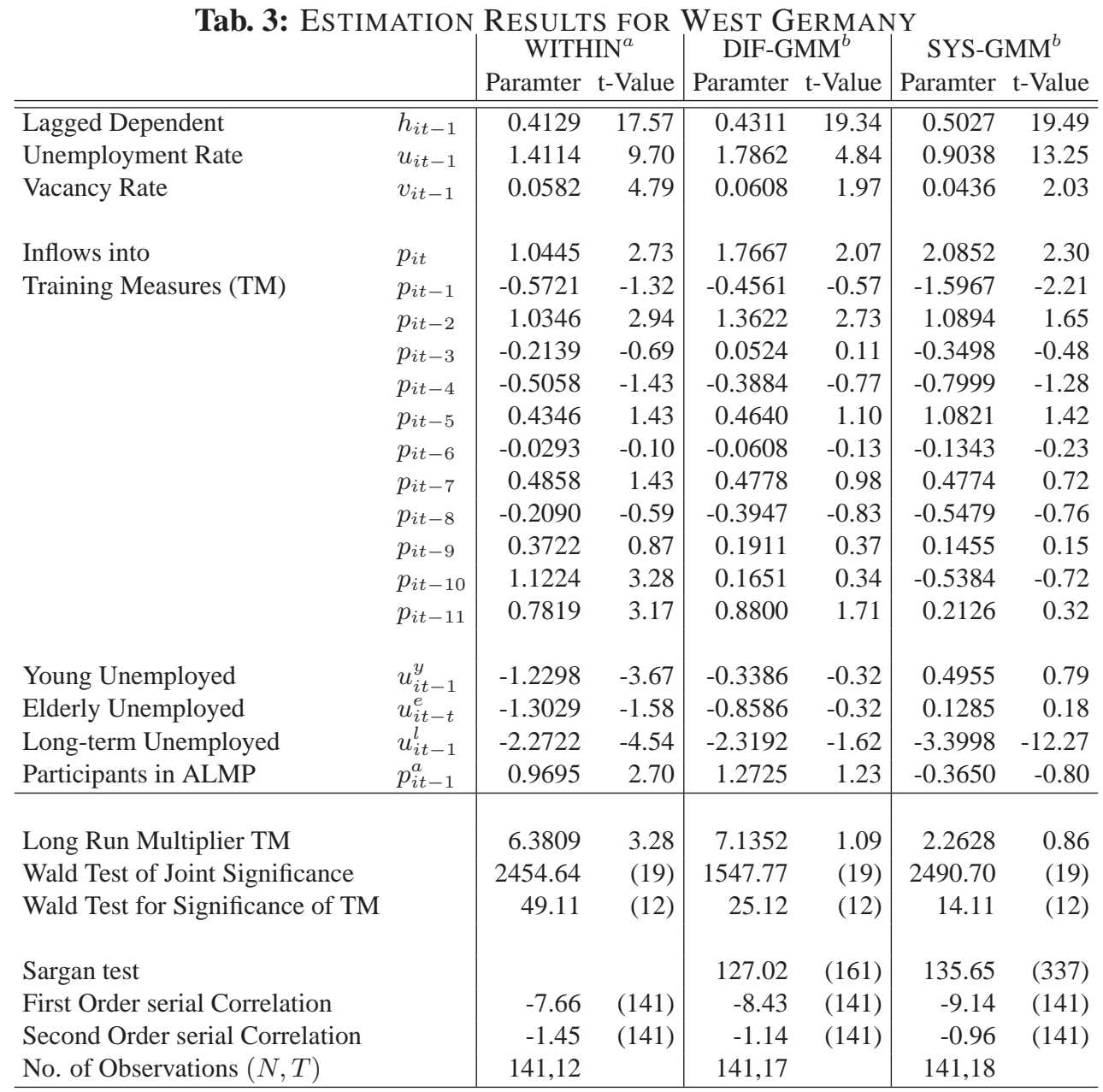

a: Standard errors are robust to heteroscedasticity

b: Two-Step estimates with corrected standard errors

Nevertheless, the estimates show a strong diversity of the impacts over time. Therefore, in order to make statements with respect to the total impact of TM we have to account for the dynamic structure of the empirical model. First, an increase of the inflows into TM has different impacts on the inflows into employment over time. Second, the dynamic model implies a dynamic adjustment of the dependent variable induced by the impact of the TM. In order to account for the dynamic structure of the model we interpret the lag-coefficients, the cumulated lag-coefficients and the long run multiplier. The lagcoefficients or dynamic multipliers describe the change of the inflows into employment at $t+g$ induced by a transitory change of the inflows into TM at $t$, i.e., $\partial m_{i(t+g)}^{*} / \partial p_{i t}$. In addition to the lag-coefficients function. 
we also present the cumulated lag-coefficients. The cumulated lag-coefficients, describe the total impact on the inflows into employment within the period $t$ up to $t+g$ due to a transitory increase of the inflows into TM in $t$. The cumulated lag-coefficient for the period $t$ up to $t+g$ is defined as $\sum_{k=0}^{g} \partial m_{i(t+k)}^{*} / \partial p_{i t}$. Analogously, the long-run multiplier represents the overall effect of a transitory increase of the inflows into TM on the inflows into employment, i.e., $\sum_{k=0}^{\infty} \partial m_{i(t+k)}^{*} / \partial p_{i t}$. The long run-multiplier are pre-

Fig. 1: LAG COEFFiCIEnTS ${ }^{A}$

LSDV

Lag Coeff.

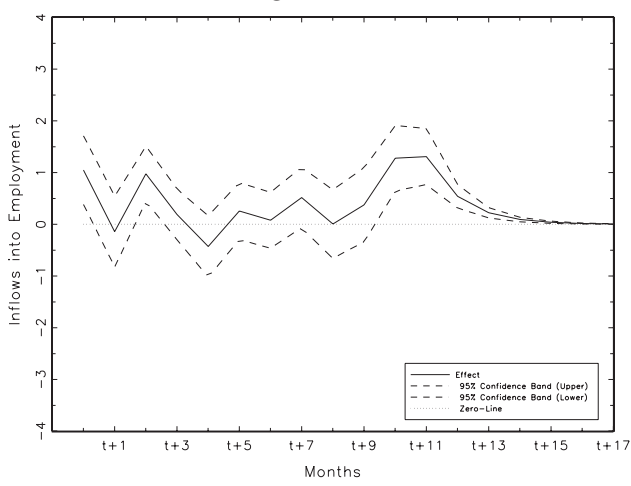

Cum. Lag Coeff.

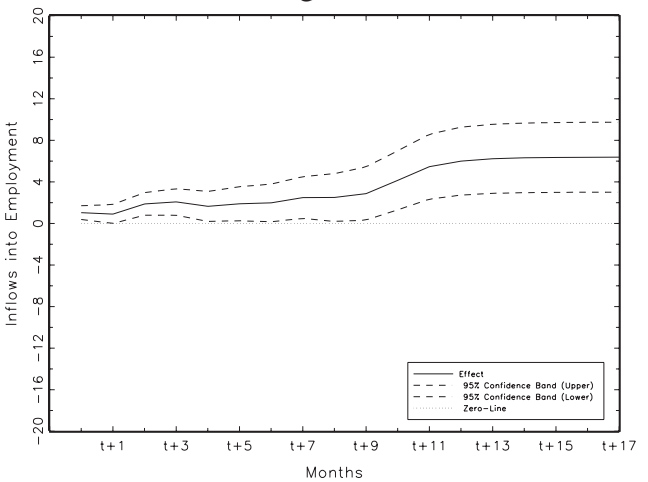

DIF-GMM

Lag Coeff.

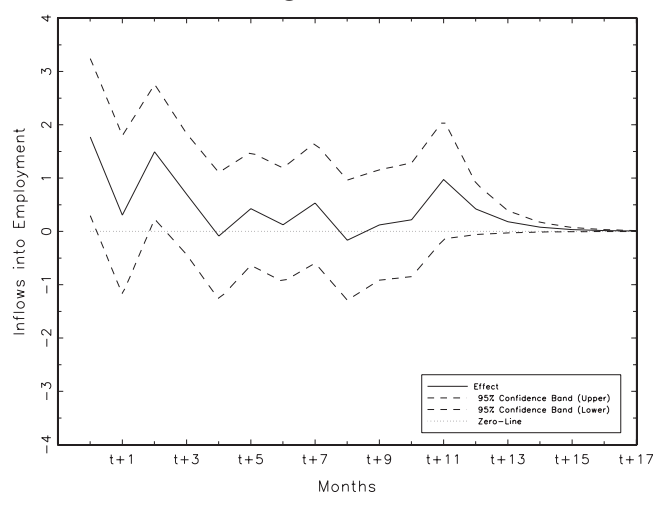

Cum. Lag Coeff.

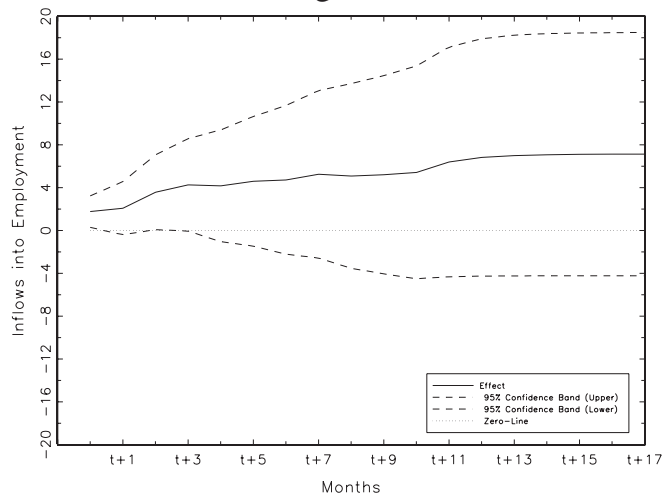

SYS-GMM

Lag Coeff.

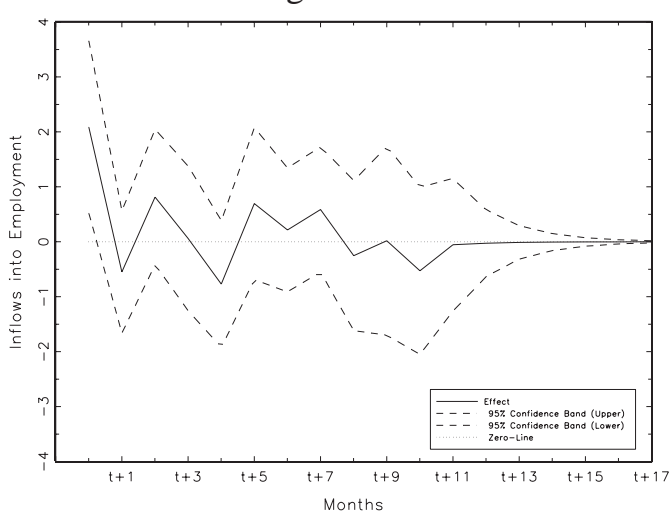

Cum. Lag Coeff.

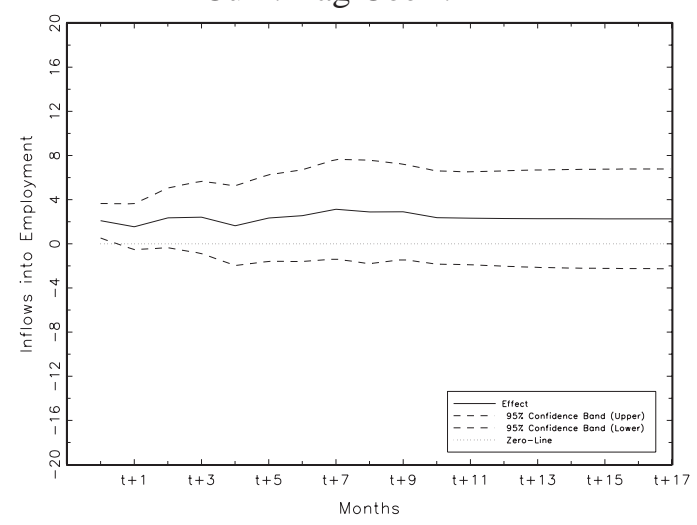

${ }^{\text {A }}$ Confidence bands are calculated by the Delta-Method 
sented in table 3 and the lag-coefficients and cumulated lag-coefficients are presented in figure 1. The standard errors of the lag coefficients and the long-run multiplier are calculated by the delta method.

Considering the lag-coefficients we find clear differences between WITHIN and both GMM estimators. For WITHIN an increase of the inflows into TM at $t$ increases the inflows into employment at $t$, $t+2$ and $t+10$ up to $t+18$. In contrast for DIF-GMM we find significant positive impacts only for $t$ and $t+2$ and for SYS-GMM only a contemporaneous impact at $t$. The associated cumulated lag-coefficients for WITHIN are throughout positive significant. For DIF-GMM the cumulated lag-coefficients are only significant for $t$ and $t+2$, and for SYS-GMM only the cumulated lag-coefficient for $t$ is significant. The long-run multipliers show a positive significant effect for WITHIN and positive but insignificant effects for DIF-GMM and SYS-GMM. However, the results from WITHIN should be interpreted very carefully since the estimates are biased. Therefore, when considering the results obtained from the GMM estimators, the empirical evidence suggest a small positive effect of the inflows into TM on the inflows into employment. This effect arises immediately (i.e. within the first three months) after an expansion of the inflows into TM.

When considering the magnitude of the effects of TM we have to account for the semi-logarithmic specification. The estimates for TM represent a percentage change of the inflows from unemployment into employment relative to the labour force caused by an absolute change of the inflows into TM relative to unemployment. Since, both variables are rates relative to the labour force and unemployment respectively, a translation of the effect into real persons is helpful. This translation is done on the basis of the means of unemployment, the labour force, the inflows into TM and the inflows from unemployment into employment. The magnitude of the effects is such that an increase of the inflows into TM relative to unemployment by 1 percentage point increases the inflows from unemployment into employment relative to the labour force by 1-2 percent. Translated into real persons, this effect implies an increase of the inflows into employment by 6-12 persons due to an increase of the inflows into TM by 100 persons.

Finally, we consider some important test statistics in order to asses the reliability of our results. The validity of the moment conditions with respect to the equations in first differences depends heavily on the absence of second order serial correlation. Arellano and Bond (1991) suggested an asymptotically normal distributed test statistic that is reported in table 3. For both GMM estimators the test statistics for serial correlation suggest that the moment conditions imposed for the equations in first differences are not affected by second order serial correlation. Additionally we present a Sargan test statistic of overidentifying restrictions to asses the validity of the moment conditions. The Sargan statistics does not reject the null hypothesis, and thus suggest that the imposed moment conditions for DIF-GMM and SYS-GMM are valid. In addition we consider the Sargan difference test in order test the validity of the extra moment conditions for the equations in levels that are imposed by SYS-GMM. The test statistic is with 8.63 and 176 degrees of freedom insignificant, i.e. the additional moment conditions imposed by SYS-GMM appear to be valid. 


\section{Conclusion}

In this paper we have conducted a macroeconometric evaluation in order to estimate the impacts of TM on the matching process. To do so, we have estimated an augmented matching function that determines the inflows from unemployment into employment by the stock of unemployed and vacancies and additionally accounts for the impact of policy. The macroeconometric analysis serves as a supplement to the microeconometric evaluation in order to test whether the effect on the participants is counteracted by possible programme effects on non-participants. In particular, this regards the analysis by Hujer, Thomsen, and Zeiss (2006), who estimate the impacts of TM on the individual unemployment duration. The econometric analysis is based on a log-linearised version of the augmented matching function. The model is estimated for West Germany with a regional panel data set. To estimate the impacts of TM on the inflows from unemployment into employment consistently we applied the GMM estimators suggested by Arellano and Bond (1991) and Blundell, Bond, and Windmeijer (2000). Moreover, the estimates are based on moment conditions that account for the possible endogeneity of the explanatory variables.

The estimation results suggest a small positive effect on the inflows into employment. This effect arises within the first three months after an increase of the inflows into TM. In the subsequent period we do not find an evidence for an impact of TM on the inflows into employment. Comparing the results from the macroeconometric evaluation with the results from the microeconometric evaluation by Hujer, Thomsen, and Zeiss (2006) we find to some extend a divergency of the results. Whereas Hujer, Thomsen, and Zeiss (2006) find a clear positive the impact on the individual transition rate within the first year after the programme start, the aggregate analysis only suggests a small effect that arise within the first three months after a programme extension. This suggests that the positive effect of TM on the microlevel is counteracted, at least to a certain extend by a negative substitution effect. That is, individual transitions from unemployment into employment that are caused by a participation in a TM, replace normal transitions from regular unemployment into employment. Since TM are a labour supply side orientated policy instrument it always runs the risk of generating only a preferential treatment of the participants especially if unemployment is for a major part driven by a shortage of labour demand. 


\section{References}

Ahn, S., And P. SCHMidt (1995): "Efficient Estimation of Models for Dynamic Panel Data," Journal of Econometrics, 68, 5-27.

Anderson, T., and C. Hsiao (1981): "Estimation of Dynamic Models with Error Components," Journal of American Statistical Association, 76 (375), 598-606.

Arellano, M., And S. Bond (1991): "Some Tests of Specification for Panel Data: Monte Carlo Evidence and an Application to Employment Equations," Review of Economic Studies, 58, 277-297.

(1998): “Dynamic Panel Data Estimation Using DPD98 for Gauss," ftp://ftp.cemfi.es/pdf/papers/ma/dpd98.pdf.

ARellano, M., AND O. Bover (1995): "Another Look at the Instrumental Variable Estimation of Error-Components Models," Journal of Econometrics, 68, 29-51.

BellmanN, L., AND R. JACKMAN (1996): “Aggregate Impact Analysis," in International Handbook of Labour Market Policy and Evaluation, ed. by G. Schmid, J. O'Reilly, and K. Schömann, pp. 143-162. Edward Elgar.

Biewen, M., B. Fitzenberger, A. Osikominu, and M. WAller (2006): "Employment Effects of Short and Medium Term Further Training Programmes in Germany in the Early 2000s," Working Paper, Goethe University Frankfurt.

Blanchard, O., and P. Diamond (1989): “The Beveridge Curve,” Brooking Papers on Economic Activity, No. 1, 1-60.

Blundell, R., And S. Bond (1998): "Initial Conditions and Moment Restrictions in Dynamic Panel Data Models," Journal of Econometrics, 87, 115-143.

Blundell, R., S. Bond, And F. WindmeiJer (2000): "Estimation in Dynamic Panel Data Models : Improving on the Performance of the Standard GMM Estimator," in Nonstationary Panels, Panel Cointegration and Dynamic Panels, ed. by B. Baltagi, vol. Advances in Econometrics 15. Elsevier Science, Amsterdam.

Boeri, T., And M. Burda (1996): “Active Labor Market Policies, Job Matching and the Czech Miracle," European Economic Review, 40, 805-817.

Bond, S., AND F. WindMEIJER (2002): "Finite Sample Inference for GMM Estimators in Linear Panel Data Models," Cemmap Working Paper cwp04/02, The Institute for Fiscal Studies.

BUNDESAGENTUR FÜR ARBEIT (2003): “Arbeitsmarkt 2002 - Amtliche Nachrichten der Bundesanstalt für Arbeit," 51. Jahrgang, Nürnberg.

(2005): "Arbeitsmarkt 2004 - Amtliche Nachrichten der Bundesagentur für Arbeit," 53. Jahrgang, Nürnberg. 
Calmfors, L., And P. Skedinger (1995): "Does Active Labour Market Policy Increase Employment? Theoretical Considerations and Some Empirical Evidence from Sweden," Oxford Review of Economic Policy, 11 (1), 91-109.

FranZ, W., AND W. SMOLny (1994): “The Measurement and Interpretation of Vacancy Data and the Dynamics of the Beveridge Curve: The German Case," in Measurement and Analysis of Job Vacancies, ed. by J. Muysken. Aldershot.

Hujer, R., S. L. Thomsen, And C. Zeiss (2006): "The Effects of Short-Term Training Measures on the Individual Unemployment Duration in West Germany," ZEW Discussion Paper No. 06-065, ZEW, Mannhaim.

Kettner, A., And E. Spitznagel (2006): "Gesamtwirtschaftliches Stellenangebot - Kräftiger Antsieg nach jahrelangem Rückgang," IAB Kurzbericht, 6/27.4.2006.

KURTZ, B . (2003): “Trainingsmaßnahmen - Was verbirgt sich dahinter?," IAB Werkstattbericht, 8.

LAYARD, R., S. Nickell, And R. JACKMAN (1991): Unemployment-Macroeconomic Performance and the Labour Market. Oxford University Press, New York.

Lehmann, H. (1995): "Active Labour Market Policies in the OECD and in Selected Transition Economies,” Working Paper No. 539-96, World Bank Policy Reasearch.

Nickell, S. (1981): "Biases in Dynamic Models with Fixed Effects," Econometrica, 49 (6), 14171426.

Petrongolo, B., And C. Pissarides (2001): "Looking into the Black Box: A Survey of the Matching Function,” Journal of Economic Literature, 29, 390-431.

Puhani, P. (1999): Evaluating Active Labour Market Policies - Empirical Evidence for Poland During Transition. ZEW Economic Studies, Vol.5, Physica-Verlag, Heidelberg, New York.

WindmeIJER, F. (2005): "A Finite Sample Correction for the Variance of Linear Two-Step Estimators," Journal of Econometrics, 126, 25-51. 